\title{
Electroacupuncture in Zucker Rat Models of Obesity and Diabetes
}

Jacqueline J. T. Liaw and Philip V. Peplow*

Department of Anatomy, University of Otago, 270 Great King Street, Dunedin, New Zealand

Obesity and diabetes are two contributing factors to the metabolic syndrome which is a state of low-grade inflammation characterized by a clustering of multiple metabolic abnormalities with obesity, hypertension, dyslipidemia, insulin resistance, and impaired glucose tolerance as its main components [1]. Randomized controlled trials in human patients have shown that acupuncture, usually electroacupuncture (EA), can correct various metabolic disturbances that contribute to hyperglycemia, overweight, hyperphagia, hyperlipidemia, inflammation, altered activity of the sympathetic nervous system, and insulin signaling defects [2]. Obesity is a lowgrade chronic inflammatory disease characterized by an excess accumulation of visceral fat especially white adipose tissue (WAT) Increased WAT mass is known to produce and secrete a wide range of pro-inflammatory mediators, resulting in an imbalance in the production of anti-/pro-inflammatory cytokines. Local proliferation of adipose tissue macrophages, in addition to macrophage infiltration from the bloodstream, occurs in the WAT [3]. The adipose tissue macrophages may thus be a major source of pro-inflammatory cytokines. Most of the obesity-related metabolic disturbances are reversible with weight loss and this is associated with a reduction in the macrophage infiltration of WAT and an improvement in the inflammatory profile of gene expression [4]. Factors derived from adipocytes and adipose tissue macrophages may play a role in the pathogenesis of insulin resistance characteristic of obesity and diabetes mellitus.

Many animal models have been used for research on the components of the metabolic syndrome and have included the Zucker rat. Zucker fatty (ZF) rats and Zucker diabetic fatty (ZDF) rats are two models commonly used to study obesity and diabetes. Both models possess a single gene $(\mathrm{fa} / \mathrm{fa})$ mutation characterized by a defect in leptin receptor. Obese ZF rats can be visually distinguished from their lean littermates by 5 weeks of age [5] due to excessive deposition of subcutaneous and visceral adipose tissue. ZDF rats possess an additional defect in $\beta$-cell gene transcription and male ZDF rats spontaneously become diabetic, representing a model of obesity associated with diabetes. Both models exhibit hyperphagia, insulin resistance, dyslipidemia, central adiposity and hypertension [6]. Miranville et al. [6] compared male ZF and ZDF rats for the level of adipose tissue infiltrated macrophages. No change in the serum levels of pro- and anti-inflammatory markers was found in obese ZF rats compared to their lean littermates. Obese ZDF rats exhibited significantly higher serum levels of the pro-inflammatory markers Rantes, monocyte chemoattractant protein-1 (MCP-1), interleukin-1 $\beta$ (IL-1 $\beta$ ) than their lean littermates with no change in the level of the anti-inflammatory adipokine, adiponectin. Their findings suggest that although both models exhibited signs of local inflammation within visceral adipose tissue, only the ZDF rats exhibit systemic inflammation

Liaw and Peplow [7] treated male obese ZF rats with EA at Zhongwan (CV12) and Guanyuan (CV4) acupoints over 2 weeks. These animals had high serum levels of leptin and insulin, and repeated application of EA significantly decreased serum tumor necrosis factor- $\alpha$ (TNF- $\alpha$ ) and IL-10. It was suggested that these findings were consistent with EA likely inhibiting proliferation and/or infiltration of macrophages in the adipose tissue of the obese ZF rats, and also stimulating the

\section{Publication History:}

Received: February 01, 2016

Accepted: March 02, 2016

Published: March 04, 2016

\section{Keywords:}

Zucker rat, Obesity, Diabetes, Electroacupuncture, Glucose control, Adipokines

release of IL-10 from the decreased numbers of adipose tissue macrophages present. There were no significant changes in body weight and blood glucose at the end of the study compared to control animals. Previous studies had shown that obesity in rodents resulted in an increase in macrophages in adipose tissue $[8,9]$ due to an increased infiltration and/or proliferation of these cells [3] and infiltration of macrophages into adipose tissue of diet-induced obese rats was inhibited by EA [10]. Inhibition of macrophage infiltration would explain the decreased serum TNF- $\alpha$ level after EA treatment. The lack of a decrease in serum IL-10 by a reduced number of macrophages in the adipose tissue would suggest that EA has altered the activation state of the macrophages from classically activated (M1 activation state) to alternatively activated (M2 activation state). In future studies, immunohistochemistry against cell surface markers should be performed to enable characterisation of macrophage phenotype more accurately.

Peplow and Han [11] have studied the effects of EA in male obese ZDF rats. Repeated application of EA to hyperglycemic obese ZDF rats of mean age 12.3 weeks at Zhongwan and Guanyuan acupoints over 2 weeks significantly lowered blood glucose. In addition, Peplow [12] found that these rats had lost their hyperinsulinemia and the serum level of leptin was decreased while that of adiponectin was raised by EA treatment, thereby resulting in a significant increase in the adiponectin:leptin ratio. It would be of interest to repeat this study and to measure serum levels of TNF- $\alpha$ and IL-10. Miranville et al. [6] had reported ZDF obese rats losing their initial hyperinsulinemia due to $\beta$-cell failure at around 10 weeks of age. Peplow and McLean [13] have also performed repeated EA treatment of older male obese ZDF rats of mean age 23.3 weeks at Zhongwan and Guanyuan acupoints over 2 weeks and showed that blood glucose was significantly lowered. Serum levels of adiponectin, leptin and adiponectin: leptin ratio were not significantly different compared to controls. Regular administration of insulin-sensitizing drugs like the thiazolidinediones (TZDs) rosiglitazone or pioglitazone to male obese ZDF rats on

*Corresponding Author: Dr. Philip V. Peplow, Department of Anatomy, University of Otago, 270 Great King Street, Dunedin, New Zealand; E-mail: phil.peplow@stonebow.otago.ac.nz

Citation: Liaw JJT, Peplow PV (2016) Electroacupuncture in Zucker Rat Models of Obesity and Diabetes. Int J Diabetes Clin Diagn 3: 114. doi: http://dx.doi. org/10.15344/2394-1499/2016/114

Copyright: @ 2016 Liaw et al. This is an open-access article distributed under the terms of the Creative Commons Attribution License, which permits unrestricted use, distribution, and reproduction in any medium, provided the original author and source are credited. 
Citation: Liaw JJT, Peplow PV (2016) Electroacupuncture in Zucker Rat Models of Obesity and Diabetes. Int J Diabetes Clin Diagn 1: 114. doi: http://dx.doi. org/10.15344/2394-1499/2016/114

Page 2 of 2

Purina 5008 fully prevented hyperglycemia or restored normoglycemia if the treatment was initiated at an age of less than 9 weeks. However more severe hyperglycemia prevailing at ages 10 to 12 weeks could only be ameliorated by TZDs, and intervention at 21 weeks of age was without a glucose-lowering effect [14] in contrast to EA application reported by Peplow and McLean [13]. The anti-diabetic action of TZDs requires adiponectin, with plasma adiponectin levels being raised through TZD effects on synthesis and secretion by WAT $[15,16]$. Adiponectin is an anti-inflammatory and insulinsensitizing adipokine. It enhances insulin sensitivity by upregulating insulin receptor substrates, which is mediated by IL-6 induction from macrophages [17].

In summary, only a few naturally occurring diabetes-prone and genetically altered rodent strains present with insulin resistance and hyperinsulinemia spontaneously. The male obese ZF rat and male obese ZDF rat have been shown to be very useful animal models for studying the effects of EA on metabolic syndrome. Female ZDF rats become diabetic when fed high-fat diets [6] and effects of EA can also be studied in this model.

\section{Competing Interests}

The authors declare that they have no competing interests.

\section{References}

1. International Diabetes Federation. IDF Worldwide definition of the metabolic syndrome.

2. Liang F, Koya D (2010) Acupuncture: is it effective for treatment of insulin resistance? Diabetes Obes Metab 12: 555-569.

3. Amano S, Cohen J, Vangala P, Tencerova M, Nicoloro S, et al. (2014) Local proliferation of macrophages contributes to obesity-associated adipose tissue inflammation. Cell Metab 19: 162-171.

4. Rossmeislova L, MaliSova L, KraCmerová J, Stich V (2013) Adaptation of human adipose tissue to hypocaloric diet. Int J Obes (Lond) 37: 640-650.

5. Boulangé A, Planche E, de Gasquet P (1979) Onset of genetic obesity in the absence of hyperphagia during the first week of life in the Zucker rat (fa/ fa). J Lipid Res 20: 857-864.

6. Miranville A, Herling AW, Biemer-Daub G, Voss MD (2012) Differential adipose tissue inflammatory state in obese nondiabetic Zucker fatty rats compared to obese diabetic Zucker diabetic fatty rats. Horm Metab Res 44: 273-278.

7. Liaw JJT, Peplow PV (2015) Effect of electroacupuncture on inflammation in the obese Zucker fatty rat model of metabolic syndrome. J Acupunct Meridian Stud.

8. Martin-Cordero L, Garcia JJ, Giraldo E, De la Fuente M, Manso R, Ortega $E$ (2009) Influence of exercise on the circulating levels and macrophage production of IL-1ß and IFNY affected by metabolic syndrome: an obese Zucker rat experimental animal model. Eur J App Physiol 107: 535-543.

9. Bouloumié A, Curat CA, Sengenès C, Lolmède K, Miranville A, et al. (2005) Role of macrophage tissue infiltration in metabolic diseases. Curr Opin Clin Nutr Metab Care 8: 347-354.

10. Wen CK, Lee TY (2014) Electroacupuncture decreases the leukocyte infiltration to white adipose tissue and attenuates inflammatory response in high fat diet-induced obesity rats. Evid Based Complement Alternat Med 2014: 473978.

11. Peplow PV, Han SM (2014) Repeated application of electroacupuncture ameliorates hyperglycemia in obese Zucker diabetic fatty rats. J Acupunct Meridian Stud 7: 1-5.

12. Peplow PV (2015) Repeated electroacupuncture in obese Zucker diabetic fatty rats: adiponectin and leptin in serum and adipose tissue. J Acupunct Meridian Stud 8: 66-70.
13. Peplow PV, McLean GT (2015) Repeated electroacupuncture: an effective treatment for hyperglycemia in a rat model. J Acupunct Meridian Stud 8: 71-76.

14. Szöcs Z, Brunmair B, Stadlbauer K, Nowotny P, Bauer L, et al. (2008) Age-dependent development of metabolic derangement and effects of intervention with pioglitazone in Zucker diabetic fatty rats. J Pharmacol Exp Ther 326: 323-329.

15. Kubota $\mathrm{N}$, Terauchi $\mathrm{Y}$, Kubota $\mathrm{T}$, Kumagai $\mathrm{H}$, Itoh $\mathrm{S}$, Satoh $\mathrm{H}$, et al. (2006) Pioglitazone ameliorates insulin resistance and diabetes by both adiponectin-dependent and -independent pathways. J Biol Chem 281: 8748-8755.

16. Maeda N, Takahashi M, Funahashi T, Kihara S, Nishizawa H, Kishida K, et al. (2001) PPARy ligands increase expression and plasma concentrations of adiponectin, an adipose-derived protein. Diabetes 50: 2094-2099.

17. Awazawa M, Ueki K, Inabe K, Yamauchi T, Kubota N, Kaneko K, et al. (2011) Adiponectin enhances insulin sensitivity by increasing hepatic IRS-2 expression via a macrophage-derived IL-6-dependent pathway. Cell Metab 13: 401-412. 